\title{
FAMILIA, AUTONOMÍA DE LA VOLUNTAD Y REPRODUCCIÓN HUMANA ASISTIDA EN LA LEGISLACIÓN MEXICANA*
}

\author{
FAMILY, AUTONOMY OF THE WILL AND ASSISTED HUMAN \\ REPRODUCTION IN THE MEXICAN LAW
}

\author{
Héctor Augusto Mendoza CÁrdenas ${ }^{* *}$
}

\begin{abstract}
Resumen: En el presente trabajo se analiza el concepto jurídico de autonomía de la voluntad y sus implicaciones en el Derecho de familia. El análisis además se efectúa en el marco de la reproducción humana asistida vista también desde el cristal del Derecho. La intención es evidenciar una serie de inconsistencias legislativas en el Derecho familiar mexicano, derivado, sin duda alguna, de la ignorancia en este tipo de temas por parte de los creadores de Derecho.

Palabras clave: Inconsistencias legislativas, autonomía de la voluntad y reproducción humana asistida, autonomía de la voluntad y Derecho familiar mexicano.
\end{abstract}

Abstract: This paper analyses the legal concept of the autonomy of the will and its implications for family law. The analysis is carried out within the framework of assisted human reproduction, as seen through the eyes of Law. The aim is to demonstrate a series of legislative inconsistencies in Mexican family law, deriving from the ignorance of lawmakers surrounding these types of topics. Keywords: Legislative inconsistencies, autonomy of the will and assisted human reproduction, autonomy of the will and Mexican family law.

SUMARIO: I. INTRODUCCIÓN; II. RESTRICCIONES GENERALES DE LAAUTONOMÍA EN LA LEGISLACIÓN FAMILIAR MEXICANA; III. COAHUILA Y LA MATERNIDAD FORZADA; IV. SAN LUIS POTOSÍ Y LA INCÓGNITA DE LOS CATORCE DÍAS; V. TABASCO Y LA MAL ENTENDIDA GESTACIÓN ASISTIDA Y SUBROGADA; VI. EL ESTADO DE MÉXICO Y LA IMPOSIBILIDAD DE DAR EN ADOPCIÓN LOS HIJOS FRUTO DE LA REPRODUCCIÓN HUMANAASISTIDA; VII. CONCLUSIONES; VIII. BIBLIOGRAFÍA.

* $\quad$ http://doi.org/10.15366/rjuam2018.38.002

Fecha de recepción: 2 de noviembre de 2018.

Fecha de aceptación: 19 de diciembre de 2018.

** Profesor-Investigador, Doctor en Derecho en la Universidad Autónoma de Nuevo León. Correo electrónico: hector.mendoza@yahoo.com.mx. Este trabajo deriva de nuestra participación en el proyecto de Investigación CEAL-AL/2017-20, «La libertad de autodeterminación en las relaciones familiares y sus límites como desafío del siglo XXI en España y América Latina». 


\section{INTRODUCCIÓN}

El fenómeno biotecnológico con sus nuevos y apasionantes descubrimientos debe ser considerado por la ciencia jurídica, ya que, históricamente, esta se había preocupado poco por reflexionar sobre fenómenos específicos relacionados con el inicio de la vida. En este orden de ideas, para la ciencia jurídica expresiones como $\mathrm{ADN}^{1}$, células madre, cigoto, blastocito o sistema nervioso central eran expresiones ajenas a la profesión. Durante siglos, el Derecho consideró, por ejemplo, que la discusión sobre la maternidad y sus implicaciones filiatorias era una discusión agotada, nada había que decir, la maternidad era un hecho objetivo y evidente. El legislador de antaño no podía imaginar todo lo que se avecinaba en estos temas. Ese legislador no podía suponer, por ejemplo, la posibilidad de generar embriones fuera del cuerpo humano, mucho menos pudo imaginar que estos embriones podrían ser criopreservados y que, de una forma u otra, entrarían en un mercado de intercambio que sin duda, tiene incidencia no solo en términos de filiación, sino también en términos de «la verdad biológica», que durante siglos fue un pilar jurídico. Hoy eso y mucho más es posible, sin embargo, el Derecho no ha sabido estar a la altura de estos cambios radicales. Es por ello que, en una especie de negación del avance biotecnológico, hemos querido ofrecer respuestas nuevas con legislaciones viejas.

Así, el Derecho y particularmente sus creadores, es decir los legisladores, se han visto rebasados por los avances biotecnológicos. No obstante, el operador jurídico ha seguido esta misma tendencia. Así, abogados litigantes y facultades de derecho, han también ignorado el tema y han despreciado el estudio del mismo.

En el presente trabajo, analizaremos las implicaciones que en términos de autonomía de la voluntad $(\mathrm{AV})^{2}$ han traído estos avances biotecnológicos ${ }^{3}$ en el Derecho familiar mexicano, ámbito jurídico que, por cierto, en el caso de México, es considerado como de orden público, lo que en la práctica significa que, bajo este argumento, nuestra legislación impone diversas restricciones a la $\mathrm{AV}^{4}$ de los individuos. Muchas de esas restricciones podrían tener sentido, en aras de proteger lo que históricamente se ha conceptualizado como «el núcleo social básico», es decir, la familia 5 .

\footnotetext{
Ácido desoxirribonucleico.

2 Para algunos puristas, la autonomía de la voluntad está más bien ligada al concepto de contrato, por lo que prefieren hablar del «poder de los cónyuges de regular autónomamente sus intereses recíprocos». Véase, por ejemplo, BARBALUCCA, V. y GALLUCCI, P., L'autonomia negoziale dei coniugi nella crisi matrimoniale, Milán (Giuffrè) 2012, p. 344. Véase también DOMINGUEZ HIDALGO, C., «Los principios que informan el derecho de familia chileno: su formulación clásica y su revisión moderna», Revista Chilena de Derecho, vol. 32 No. 2, p. 212. Disponible en $<$ https://papers.ssrn.com/sol3/papers.cfm?abstract_id $=2640200>$. [Consultado el 08/01/2019].

3 UNGARI, P., Bioética, nuevos derechos y autonomía de la voluntad, Buenos Aires (La Rocca), 2000, p. 135.

4 TOMMASINI, R., Autonomia privata e rimedi in trasformazione, Turín (Giappichelli), 2013, p. 1.

5 ROMO MORALES, G., «La familia como institución y universal. Análisis de los cambios modernos», en ROMO MORALES, G. (coord.), La familia como institución. Cambios y permanencias, México, (Ed. Universidad de Guadalajara), 2016, p. 115.
} 
Antes de abordar el tema que nos ocupa, es pertinente señalar que en México existen tantos códigos civiles como entidades de la República y, en su gran mayoría, la materia familiar está incluida dentro de la legislación civil. Algunas excepciones se dan en los siguientes estados: Hidalgo, Michoacán, Morelos, San Luis Potosí, Sinaloa, Sonora, Yucatán y Zacatecas, que han sustraído de la legislación civil los aspectos familiares y han creado sus propios códigos familiares.

\section{RESTRICCIONES GENERALES DE LA AUTONOMÍA EN LA LEGISLACIÓN FAMILIAR MEXICANA}

Como todos estaremos de acuerdo, la AV en un sentido amplio se inserta en un concepto más general, que no es otro que el de libertad ${ }^{6}$. Es así por ejemplo que la Corte Interamericana de los Derechos Humanos (CIDH) ha establecido que «[e]l concepto de libertad y la posibilidad de todo ser humano de auto-determinarse y escoger libremente las opciones y circunstancias que le dan sentido a su existencia, conforme a sus propias opciones y convicciones, es un derecho humano básico, propio de los atributos de la persona, que se proyecta en toda la Convención Americana»?

Entonces, el ejercicio de la AV como un derecho particular responde al ejercicio de ese derecho superior de libertad del ser humano para autodeterminarse, cuya única restricción debería ser la no afectación a los derechos de terceros ${ }^{8}$.

No obstante lo anterior, por considerarse la familia como una institución jurídica de orden público ${ }^{9} \mathrm{y}$ al asumirse que el Estado tiene un interés particular en proteger a esta, la legislación mexicana, siguiendo ideas conservadoras ${ }^{10}$, impone diversas restricciones al ejercicio libre y autónomo de la voluntad en esta materia.

6 FENOUILLET, D. y VAREILLES-SOMMIÉRES, P. (dirs), La contractualisation de la famille, París (Ed. Económica), 2001, p. 64.

$7 \mathrm{CIDH}$, «Artavia Murillo vs. Costa Rica», 28/11/2012. Disponible en: $<$ http://observatoriointernacional. com/?p=795>. [Consultado el 08/01/2019].

8 KEMELMAJER DE CARLUCCI, A., «La autonomía de la voluntad en el derecho de familia argentino», en GRAHAM, M. y HERRERA M. (dirs.), Derecho de las Familias, Infancia y Adolescencia. Una mirada crítica y contemporánea, $1{ }^{\mathrm{a}}$ ed., Buenos Aires (Infojus), 2014 p. 18. Disponible en $<$ http://www.saij.gob.ar/docs-f/ ediciones/libros/DERECHO\%20DE\%20LAS\%20FLIAS\%20compl\%20digital\%20(3).pdf>. [Consultado el 20/01/2019].

9 BERNAL-FANDIÑO, M., «El principio de solidaridad como límite a la autonomía privada». Revista Jurídicas, 13 (2), julio-diciembre 2016, p. 65. Disponible en $<$ http://vip.ucaldas.edu.co/juridicas/downloads/ Juridicas13(2)_5.pdf $>$. [Consultado el 09/01/2019].

10 Véanse por ejemplo las opiniones de SALINAS QUIJADA, F., «La autonomía de la voluntad en el artículo 90 del código civil en el derecho civil de Navara: sus concordancias y diferencias», Revista Ius Canonicum, 1982, Vol. XXII (No44), p. 799. Disponible en <https://www.unav.edu/publicaciones/revistas/index.php/iuscanonicum/article/download/19206/15775>. [Consultado el 10/01/2019]. 
Entre las más evidentes libertades en cuanto al ejercicio de la $\mathrm{AV}$ en el terreno familiar, debemos señalar en primer término, la libertad consagrada en la propia Constitución Mexicana, relativa a la posibilidad de tener el número de hijos en el espacio de tiempo que así lo decida cada ciudadano. En cuanto a las libertades relacionadas con la AV específicamente establecidas por el Derecho de familia, tenemos, entre otras, la elección del nombre de los hijos, la forma en que habrán de ser educados, la religión que se les inculca, etc.

Ahora bien, en México siguen existiendo en algunas entidades de la República diversas y serias restricciones en materia de matrimonio, divorcio o alimentos. Así, ciertas entidades de la República siguen exigiendo, por ejemplo, que el matrimonio sea de carácter heterosexual, condicionándolo inclusive a la reproducción de la especie. Esta visión tradicional y conservadora implica una franca intromisión en el proyecto de vida de los ciudadanos y consecuentemente representa una seria restricción al ejercicio libre de la $\mathrm{AV}$, toda vez que, en todo caso, dicha visión pretende negar la nueva realidad social, en la que la estabilidad del matrimonio ha dejado de ser la piedra angular del mismo ${ }^{11}$.

En lo que concierne al divorcio, al menos un tercio de las entidades de la República continúan con el viejo sistema de causales en sus legislaciones civiles o familiares, lo que representa, en comparación con el divorcio incausado, otra franca limitación al ejercicio autónomo de la voluntad ${ }^{12}$.

No obstante lo dicho, en México y por vía jurisprudencial se ha venido ampliando dicho ejercicio de la autonomía decisional. Así, la Suprema Corte de Justicia de la Nación $(\mathrm{SCJN})$ ha resuelto en diversas ocasiones que la $\mathrm{AV}$ responde a un derecho humano superior, que no es otro que el derecho al libre desarrollo de la personalidad ${ }^{13}$.

Así, si bien existen diversas manifestaciones, particularmente en las legislaciones locales relacionadas con el Derecho de familia que limitan el libre ejercicio de la autonomía de los individuos, nuestro máximo tribunal en concordancia con la CIDH, ha venido sosteniendo que el libre desarrollo de la personalidad (entendido como un ejercicio de la $\mathrm{AV}$ individual) es un derecho humano superior, susceptible de la más amplia protección por parte del Estado mexicano.

En concreto, el libre desarrollo de la personalidad implica la libre elección de los individuos de sus planes de vida ${ }^{14}$, consecuentemente, frente a este derecho humano,

11 ARANA DE LA FUENTE, I., «Concepto y función social del matrimonio. Los sistemas matrimoniales», en DIEZ PICAZO GIMÉNEZ, G. (coord.), Derecho de Familia, Pamplona (Thomson Reuters-Civitas), 2012, p. 167.

12 DE AMUNÁSTEGUI RODRÍGUEZ, C., «Libertad de pacto en el régimen de separación de bienes», en RAMS ALBESA, J. y otros (coords.), Autonomía de la voluntad y negocios jurídicos de familia, Madrid (Dykinson), 2009, p. 128.

13 Véase tesis jurisprudencial con registro 2009591, instancia: Primera Sala, Libro 20, julio de 2015, Tomo I. Disponible en $<$ https://sjf.scjn.gob.mx/SJFSist/Paginas/DetalleGeneralV2.aspx?id=2009591\&Clase=Detall eTesisBL $>$. [Consultado el 15/10/2018].

14 Idem. 
«el Estado tiene prohibido interferir en la elección de éstos, debiéndose limitar a diseñar instituciones que faciliten la persecución individual de esos planes de vida y la satisfacción de los ideales de virtud que cada uno elija, así como a impedir la interferencia de otras personas en su persecución. En el ordenamiento mexicano, el libre desarrollo de la personalidad es un derecho fundamental que permite a los individuos elegir y materializar los planes de vida que estimen convenientes, cuyos límites externos son exclusivamente el orden público y los derechos de terceros».

Cabe señalar que, no obstante lo anterior, muchas legislaturas estatales simplemente han hecho caso omiso de lo dicho por la SCJN y no han modificado sus legislaciones. En consecuencia, si bien la SCJN reconoce diversos derechos relacionados con la AV de incidencia familiar, en los hechos, mientras no se hagan las adecuaciones legislativas correspondientes, los ciudadanos siguen viéndose privados de diversos derechos, ya que, en todo caso, para hacer valer la jurisprudencia, es necesario demandar a las autoridades estatales invocando dichas tesis jurisprudenciales, lo que en la práctica representa una limitación para muchos ciudadanos que carecen de recursos económicos para hacer frente a un juicio de tales características.

Finalmente, en materia de divorcio, cabe señalar que el 15 de septiembre de 2017 se modificó el artículo 73, fracción XXX, de la Constitución Política Mexicana y se ordenó la centralización de la legislación procesal, tanto civil como familiar. De acuerdo al decreto antes aludido y a los transitorios del mismo, en un plazo de 180 días el Congreso de la Unión debía emitir la nueva legislación procesal tanto civil como familiar de aplicación en toda la República. Nos queda claro que, si bien la modificación alude a la parte procesal, dicha modificación constitucional, cuando cristalice, alguna incidencia tendrá en la parte de fondo de los asuntos familiares, por ejemplo en materia de divorcio.

Resulta pertinente precisar que, al momento de escribir el presente texto ${ }^{15}$, el Congreso de la Unión ha omitido emitir las correspondientes leyes procesales, no obstante que han transcurrido en exceso los 180 días de plazo que se habían establecido.

Ahora bien, en los siguientes apartados, abordaremos diferentes restricciones al libre ejercicio de la AV relacionados con las técnicas de reproducción humana asistida (RHA) en la legislación familiar mexicana. Restricciones que en la mayoría de los casos revelan, o bien una ideología particular llevada al Derecho, o una franca ignorancia de los diferentes aspectos que atañen al tema que nos ocupa.

Insistimos en el hecho de que este trabajo se limita al análisis de diversos códigos civiles o familiares de la legislación mexicana, ya que el mismo es producto de nuestra participación en el proyecto de Investigación CEAL-AL/2017-20, «La libertad de autodeterminación en las relaciones familiares y sus límites como desafío del siglo XXI en España y América Latina».

15 Octubre de 2018. 
Somos conscientes, sin embargo, de que la AV en materia familiar es un tema en pleno desarrollo tanto en México como en muchas partes del mundo, particularmente, y como lo hemos mencionado, como consecuencia de la aparición de las diversas tecnologías reproductivas que se han desarrollado en las últimas décadas. Tecnologías que, sin duda, vinieron a transformar el panorama jurídico en materia familiar, particularmente en los temas de AV y filiación.

\section{COAHUILA Y LA MATERNIDAD FORZADA}

En el estado de Coahuila, hasta hace relativamente poco (finales de $2015^{16}$ ) podíamos encontrar en su Código Civil una disposición que prácticamente imponía la paternidad o maternidad en una franca violación del libre ejercicio de la AV de las partes involucradas.

En el Código Civil de esta entidad se podía leer en su artículo 488 lo siguiente: «[s]i el matrimonio se disuelve por muerte, divorcio o nulidad, la mujer no podrá ser inseminada con material genético de quien fuera su marido. Si hubiere un óvulo fecundado en forma extracorpórea, deberá ser implantado a la viuda, divorciada o a la mujer cuyo matrimonio se anuló.

Si el hijo nace dentro de los trescientos días de disuelto el matrimonio, o de que el óvulo fue implantado, quedará atribuida la paternidad a quien era el marido de la madre».

Como podemos apreciar, Coahuila prohibía expresamente la inseminación artificial post-mortem ${ }^{17}$. Sin embargo, ante la muerte del varón, en casos de divorcio o nulidad, si existía un óvulo fecundado, este debía ser implantado en dicha mujer.

Nótese la utilización del verbo «deber», lo que implica que, imperativamente, cualquier mujer en estas circunstancias estaría obligada a hacerse implantar dicho óvulo fecundado.

Cabe señalar además que la fracción quinta del artículo 485 del mismo Código, establecía una prohibición expresa relacionada con el diagnóstico genético preimplantacional ${ }^{18}$, lo que implicaba que una vez generado un embrión, independientemente de cualquier circunstancia, el mismo debería ser implantado en la mujer. Es evidente que en casos como el que se comenta la AV de la viuda, divorciada o mujer cuyo matrimonio se anuló resultaba irrelevante, ya que, por una disposición normativa de aplicación obligatoria, lo que ella

\footnotetext{
16 Por la gravedad (en nuestra opinión) de las disposiciones, incluimos este apartado sobre el Código de Coahuila, que fue derogado hacia finales del 2015.

17 MENDOZA CÁRDENAS, H. A., La Reproducción Humana Asistida desde una perspectiva Biojurídica, México (Fontamara), 2011. p. 148.

18 Para más información sobre el diagnóstico preimplantacional, véase VILLELA CORTÉZ F. y LINARES SALGADO J., «Diagnostico genético prenatal y aborto. Dos cuestiones de eugenesia y discriminación», Revista de Bioética y Derecho, vol. 24, 2012 p. 31 y ss. Disponible en $<$ http://scielo.isciii.es/scielo.php?script=sci_ar ttext\&pid=S1886-58872012000100004>. [Consultado el 21/01/2019].
} 
piense u opine es irrelevante, ya que, como se señaló, el verbo utilizado por el legislador fue el verbo «deber», lo que hace de la norma una imposición.

En nuestra opinión, disposiciones como las anteriores terminan convirtiendo a las mujeres en simples incubadoras, ya que, como se puede observar, una vez fecundado el embrión, la mujer (viuda, divorciada o a quien se le haya anulado su matrimonio) no podría ni siquiera opinar.

Como lo señalamos, venturosamente esta legislación fue derogada y en diciembre de 2015 se creó una nueva Ley para la Familia del Estado de Coahuila de Zaragoza, en la que ya no se utiliza el verbo «deber». En la nueva legislación, en su artículo 373, actualmente se establece que «si hubiere un óvulo fecundado en forma extracorpórea, para que el mismo pueda ser implantado luego de la terminación de la relación o la disolución del vínculo o de la muerte del varón se necesita consentimiento por escrito de la mujer receptora».

El giro fue radical, pues pasaron de imponer normativamente ciertas obligaciones a las mujeres, a reconocer ampliamente la $\mathrm{AV}$ de estas últimas, al exigir en la legislación vigente el consentimiento precisamente de estas en el caso de que deseen hacerse implantar el óvulo fecundado. No obstante lo anterior, y teniendo como referencia el icónico caso «Davis vs Davis $\rangle^{19}$, la nueva legislación coahuilense viola, en nuestra opinión, el ejercicio de la AV de los varones, en cuanto al derecho a «no ser padre», pues el mismo artículo establece que «para que el mismo [el óvulo fecundado] pueda ser implantado luego de la terminación de la relación o la disolución del vínculo o de la muerte del varón se necesita consentimiento por escrito de la mujer receptora».

Como se puede apreciar, dando una segunda lectura al mismo artículo, basta el consentimiento de la mujer, particularmente en los casos de divorcio o nulidad, para que el óvulo fecundado les pueda ser implantado. El problema en este caso, es que si la relación ya concluyó, por ejemplo por nulidad o por divorcio, parece que el varón nada podría opinar sobre la implantación del óvulo fecundado extracorpóreamente, lo que en este caso derivaría en la imposición de diversas cargas por vía de las obligaciones procedentes de la paternidad. Así, en la legislación anterior, se imponía una especie de maternidad obligatoria para las mujeres y en la actual, puede imponerse (si la mujer decide implantarse el óvulo fecundado) una paternidad obligatoria a los varones ${ }^{20}$.

Curiosamente en el caso de la implantación post mortem si se cuidó este detalle, ya que el artículo 372 establece: «[e]l consentimiento a que se refiere el artículo anterior, quedará revocado con la muerte de quien lo otorgó, si antes no se hubiere producido la fecundación, salvo que en la escritura pública correspondiente se especifique que habrá de continuarse con el procedimiento para la fecundación humana asistida aun cuando aquélla ocurriera».

\footnotetext{
19 Véase al respecto, MENDOZA CÁRDENAS, H. A., La Reproducción Humana Asistida desde una perspectiva Biojurídica, ob. cit. p. 148.

20 LAMM, E., Gestación por sustitución: ni maternidad subrogada ni alquiler de vientres, Barcelona (Universidad de Barcelona), 2013, p. 35.
} 


\section{SAN LUIS POTOSÍ Y LA INCÓGNITA DE LOS CATORCE DÍAS}

Otro caso interesante es el de San Luís Potosí, ya que su Código Familiar plantea múltiples inconsistencias en relación al libre ejercicio de la AV de los individuos.

Iniciemos con el artículo 240 de la legislación familiar potosina, en el que se establece que

«[s]i el matrimonio se disuelve por muerte, divorcio o nulidad, la mujer no podrá ser inseminada con gametos de quien fuera su marido. Si hubiere un óvulo fecundado en forma extracorpórea, podrá ser implantado solo en el caso de la mujer viuda, pero ello deberá hacerse dentro de los catorce días siguientes al fallecimiento del marido, a efecto de que pueda atribuírsele la paternidad, pues de no hacerlo dentro del término correspondiente, bajo ninguna circunstancia podrá atribuírsele dicha paternidad».

En principio se reconoce la posibilidad de la implantación de un embrión post mortem, aunque, sin razón aparente, se prohíbe la inseminación artificial también post mortem. Lo extraño del caso es que, en términos de la AV, la implantación post mortem de un óvulo fecundado deba ser en un plazo improrrogable de catorce días.

En este sentido, resulta un misterio inescrutable saber por qué el legislador impuso un plazo de catorce días. La pregunta obligada es: ¿por qué no 13? o ¿por qué no 15? Evidentemente nos encontramos frente a otra franca violación del derecho al libre ejercicio de la AV de las mujeres. Cabe señalar, en este caso, que la implantación de un embrión, debe responder a criterios médicos y no jurídicos, por más que la legislación imponga un plazo, seguramente en muchos de los casos no podrá ser así, precisamente por razones de técnica médica.

Adicionalmente, en el tercer párrafo del artículo 239 de este nuevo Código Familiar potosino, se puede leer lo siguiente: «[s]ólo se permitirá la reproducción heteróloga cuando ha sido médicamente diagnosticada, y se compruebe fehacientemente que no existe otra opción para realizarla».

Como podemos observar, más allá de la limitante que este tipo de redacción implica en términos de la $\mathrm{AV}$, es evidente que el legislador no ha entendido el tema relacionado con la RHA, pues la «reproducción heteróloga» no es un padecimiento. La reproducción heterologa es una de las diversas técnicas de RHA, por lo que es imposible diagnosticarla. Es decir, se diagnostican padecimientos o enfermedades, como puede serlo la esterilidad o la infertilidad, pero es imposible diagnosticar una técnica como lo es «la reproducción heteróloga». Esto evidencia, como lo hemos venido sosteniendo, la ignorancia en la materia por parte de los legisladores, lo que, como es evidente, no les impide legislar en la materia. 
Adicionalmente, en San Luis Potosí, ignorando las nuevas realidades familiares y también en cuanto a la AV en relación a la familia, se establece en el mismo artículo 239 que «[p]odrán ser destinatarios de las técnicas de reproducción humana asistida, quienes se encuentren unidos en matrimonio o concubinato y derivado de cuestiones de esterilidad o infertilidad, así diagnosticadas, no hayan podido engendrar o concebir». Lo que implica una franca discriminación, pues las técnicas de RHA, solo pueden ser utilizadas por personas unidas en matrimonio o en concubinato, como si estas dos figuras fueran las únicas fuentes creadoras de derechos familiares.

Por último, en San Luis Potosí se encuentra expresamente prohibida la maternidad subrogada. Así lo ordena el artículo 243 del Código Civil, que establece categóricamente que «[e]s inexistente la maternidad substituta y por lo mismo no producirá efecto legal alguno».

Sin embargo, el segundo párrafo de este artículo establece que «si un embrión fuese implantado en una mujer distinta a la cónyuge o concubina, la maternidad se le atribuirá a la primera».

Es decir, el legislador potosino ignora deliberadamente la realidad biológica, pues en caso de que se diera una maternidad subrogada, la maternidad se atribuirá, por disposición legal, a la gestante, ignorándose nuevamente el elemento volitivo ${ }^{21}$.

Lo que se contradice con el artículo 244 del mismo Código Civil, pues este establece que «[1]a gestación de un embrión, cuya progenitora hubiese fallecido, no afectará la filiación del gestado cuando se trate de reproducción humana asistida».

De la redacción es de suponer que para gestar un embrión cuya progenitora falleció sería necesario el útero de otra mujer, es decir, sería necesario recurrir a una gestante sustituta. En este contexto, parece que, si un embrión es implantado en otra mujer si la progenitora de dicho embrión fallece, se le reconocerá como su hijo, pero, si no fallece, se le atribuirá a la gestante sustituta.

\section{TABASCO Y LA MAL ENTENDIDA GESTACIÓN ASISTIDA Y SUBROGADA}

Si bien en Tabasco desde 1997 se reconocía la posibilidad de recurrir a la gestación por encargo, es a principios de 2016 cuando, mediante una modificación de la legislación civil, se regula (o se intenta regular) el tema de la gestación por encargo. Así, a partir de 2016 el Código Civil de Tabasco cuenta con un apartado denominado «de la Gestación Asistida y Subrogada».

Ahora bien, es evidente que quienes elaboraron esta reforma del Código Civil desconocen profundamente el tema, ya que, a lo largo del capítulo correspondiente, podemos

${ }^{21}$ LAMM, E., Gestación por sustitución: ni maternidad subrogada ni alquiler de vientre, ob. cit, p. 25. 
encontrar un amplio repertorio de contradicciones e inconsistencias, que, sin lugar a dudas, vulneran la AV de los individuos. Veamos a qué nos referimos.

En principio, en la renovada legislación de Tabasco, se establece que estos procedimientos (Gestación Asistida y Subrogada) solo son permitidos para cónyuges o concubinos, dejando de lado por ejemplo a hombres o mujeres en soltería, lo que representa una franca violación de los derechos humanos, tanto desde la perspectiva constitucional ${ }^{22}$ como convencional, particularmente en lo referente a la no discriminación, pero también a diversos principios que la SCJN ha ido ampliando, tales como el ejercicio libre al desarrollo de la personalidad y proyecto de vida de cada individuo, lo que evidentemente representa una restricción impuesta desde el Estado al libre ejercicio de la AV, en este caso de evidente incidencia en el ámbito familiar.

En este orden de ideas, si bien la legislación analizada permite, vía consentimiento informado, la inseminación post mortem, reitera (de manera discriminatoria) que estos procedimientos están reservados para cónyuges o concubinos. Sin embargo, va más allá, dado que, en términos de la $\mathrm{AV}$, no parece haber razones para permitir la inseminación post mortem y excluir la posibilidad de la implantación de un óvulo fecundado también post mortem, alternativa que, en nuestra opinión, por ignorancia y por omisión legislativa, no fue ni siquiera considerada.

Así pues, en Tabasco, haciendo valer el principio de AV, es posible la criopreservación de gametos para ser utilizados post mortem, pero al mismo tiempo la AV se ve limitada en la medida en que la criopreservación de embriones para ser utilizados post mortem no es permitida $^{23}$.

Port otra parte, en el caso de la gestación sustituta o por encargo, la legislación tabasqueña reconoce dos modalidades diferentes, una mediante una figura denominada subrogada y otra denominada sustituta.

Así, se entiende por gestante subrogada a aquella mujer que es inseminada ${ }^{24}$ y que, consecuentemente, aporta sus óvulos, la que después del parto deberá entregar al recién nacido a la madre contratante, esto mediando una adopción plena. Ahora bien, en una segunda categorización se establece que la gestante sustituta es aquella mujer que es contratada, exclusivamente, para portar en su vientre un embrión obtenido mediante fecundación in vitro con el material genético de la pareja o persona contratante. Entonces, subrogada es

22 LÓPEZ AGUILAR, J. F., Derechos fundamentales y libertad negocial: sobre el espacio constitucional para la autonomía de la voluntad entre particulares, Madrid (Ministerio de Justicia), 1990, p. 20.

${ }_{23} \mathrm{Si}$ bien es cierto que bajo el principio de que «todo aquello que no está expresamente prohibido se encuentra permitido» podríamos pensar que es posible criopreservar embriones para su implantación post mortem, lo anterior no es evidente, ya que implicaría por ejemplo destinar reglas para su criopreservación o para la filiación derivada de este tipo de hipótesis, lo que no existe en el código que se comenta.

24 Aunque no se dice, de la redacción de todo el apartado, es de concluir que es inseminada con material genético del varón de la pareja o incluso de terceros, pues la ley reconoce la inseminación heteróloga. 
aquella mujer que facilita su vientre y aporta material genético, en tanto que la sustituta es aquella que no aporta material genético alguno y solamente facilita su vientre para la gestación para otros.

Una vez hechas las anteriores precisiones, un apartado francamente inquietante es el contenido en el último párrafo del artículo 380 bis 3 del Código Civil, en el que se establece que en caso de que la gestante sustituta o su cónyuge demanden la paternidad o maternidad, solamente podrán recibir, previo reconocimiento de su cónyuge, la custodia del producto de la inseminación, únicamente cuando se acredite la incapacidad o muerte de la madre o padre contratantes. Decimos que resulta inquietante pues el mismo contiene un sinfín de contradicciones que, sin duda, tienen una incidencia directa en la AV y que analizaremos enseguida.

Primeramente, hay que insistir en que la gestante sustituta, tal y como la define la Ley, es aquella mujer que recibe en su vientre un embrión producto del material genético de la pareja contratante, es decir, en este caso, dicha gestante no es inseminada ni aporta material genético propio. Siendo así, resulta absurdo que esta mujer pudiera, como lo establece el artículo 380 bis 3 antes transcrito, demandar la maternidad, ya que, en tales condiciones, es evidente que el recién nacido no debería contar con ninguna vinculación biológica con dicha mujer ya que de acuerdo a las definiciones de la Ley, la gestante sustituta solo facilita su vientre para recibir en el mismo un embrión obtenido mediante fecundación in vitro con el material genético de la pareja o persona contratante.

Véase pues, en términos de la AV, cómo es que la legislación de Tabasco secuestra dicha autonomía a los padres verdaderamente biológicos y por una ficción absurda e incongruente, dicha AV se la traslada a la gestante sustituta quien, insistimos, no aportó material genético alguno en relación al nacido. Así, a pesar de que en este caso se trata de una mujer que solo facilita su vientre y no aporta material genético, puede, sin embargo, demandar la maternidad del recién nacido. Parecería que, en este caso, el legislador tabasqueño adoptó (erróneamente) la postura que Eleonora Lamm denomina como «teoría de la preferencia de la gestante», sin importarle, en el caso particular, el componente biológico del gestado ${ }^{25}$.

Pues bien, si ya la anterior hipótesis es ilógica, más ilógico e incongruente resulta, en relación a la $\mathrm{AV}$ de la pareja contratante, que la misma Ley disponga que el cónyuge de la gestante sustituta (la que solo recibe en su vientre un embrión ajeno genética y biológicamente a ella) pueda reclamar también la paternidad del recién nacido. Cónyuge que -evidentemente- tampoco aportó material genético alguno.

Es indudable que el legislador tabasqueño no domina o no entiende el tema implicado en la RHA, ya que confunde las definiciones establecidas por él mismo en el nuevo Código Civil.

${ }_{25}$ LAMM, E., Gestación por sustitución: ni maternidad subrogada ni alquiler de vientres, cit., p.31. 
Por último, también resulta sorprendente que el legislador de Tabasco no solo no conozca las implicaciones jurídicas de la RHA, sino que además confunda conceptos básicos del Derecho de familia, ya que mezcla paternidad con custodia.

Efectivamente, en el artículo 380 bis 3 del Código Civil, reiteradamente transcrito, se establece que «en caso de que la gestante sustituta o su cónyuge demanden la paternidad o maternidad, solamente podrán recibir, previo reconocimiento de su cónyuge, la custodia del producto de la inseminación, únicamente cuando se acredite la incapacidad o muerte de la madre o padre contratantes».

Así, se equipara la paternidad o maternidad con la custodia, dos elementos que en el ámbito jurídico familiar, tienen peso e implicaciones completamente diferentes. La paternidad o maternidad aluden al concepto jurídico de «patria potestad», en tanto que la custodia es una figura jurídica mucho más limitada en sus alcances.

Otro absurdo relacionado con la AV es que, sin razón aparente alguna, se imponen diversos criterios de edad tanto para la mujer contratante como para la gestante. En el caso de la gestante, la Ley ordena que deberá encontrarse en un rango de edad de entre veinticinco y treinta y cinco años, en tanto que la contratante deberá tener entre veinticinco y cuarenta años. Podemos suponer que un rango de edad para la gestante responde a ciertos criterios médicos que tienen que ver con el embarazo, pero fijar un rango de edad para la contratante y no hacerlo así en el caso de los varones (ya que respecto de la edad de estos no se dice nada) es, indudablemente, una franca violación en términos de discriminación.

Adicionalmente, otra limitación en términos de la AV la encontramos en la parte final del artículo 380 bis 5 en donde se establece que «[u]na vez que sea suscrito el instrumento jurídico ante Notario Público, deberá ser aprobado por el Juez competente, a través de procedimiento judicial no contencioso, en el que se reconozca el vínculo entre los contratantes y el feto, a su vez que la gestante, y en su caso, su cónyuge o concubino renuncien a cualquier derecho de parentesco con el recién nacido». Efectivamente, ahora la AV se ve sujeta a la autorización judicial, ya que como es evidente, el juez podría no aprobar el contrato entre solicitante(s) y mujer gestante. Pero, igualmente, queda sujeta a que la gestante y, en su caso, su cónyuge o concubinario renuncien a cualquier derecho de parentesco con el recién nacido. Esta disposición es genérica, pero recordemos que en el caso de la gestante sustituta, de acuerdo a las definiciones del mismo Código, no existe vinculación genética ya que solo facilita su vientre, por lo que no existe, al menos desde una perspectiva biológica, parentesco alguno que demandar.

Por último, en el Código Civil de esta entidad podemos encontrar otro absurdo más ya que en el artículo 349 podemos leer que «[p]uede reconocerse al hijo que aún no ha nacido, incluyendo a los concebidos por cualquier método de inseminación artificial o fertilización in vitro, aun cuando no se encuentre en el útero materno en el momento del reconocimiento». 
Como es sabido, mientras un óvulo fecundado no se transfiera al útero de la mujer, este debe estar bajo condiciones de criopreservación. No obstante este hecho, la legislación tabasqueña permite que ese o esos embriones puedan ser reconocidos como hijos. Si bien es cierto que hemos señalado primordialmente diversas restricciones a la $\mathrm{AV}$ por exceso legislativo, debemos confesar que, en este caso, gracias al exceso legislativo nos encontramos (aunque solo sea por una ficción jurídica) con una extensión del ejercicio de la AV. Pues, por irracional que parezca, es posible, en un ejercicio de la AV, reconocer a uno (o varios) embriones congelados en nitrógeno líquido.

Cabe precisar que, de aceptar hipótesis como la antes planteada, es muy probable que tuviéramos que concluir que los padres y demás personal médico que contribuyeron a la criopreservación, estarían cometiendo -al menos- el delito de secuestro, ya que al poder reconocer al embrión congelado como hijo, supondríamos que este es considerado como una persona y en consecuencia, tomando en cuenta las propias disposiciones contenidas en el Código Penal de Tabasco, tendríamos que concluir que esa «personita» ${ }^{26}$ se encuentra secuestrada, lo que implica una pena privativa de la libertad de hasta cuarenta años de prisión.

\section{ELESTADO DE MÉXICO Y LA IMPOSIBILIDAD DE DAR EN ADOPCIÓN LOS HIJOS FRUTO DE LA REPRODUCCIÓN HUMANA ASISTIDA}

En esta entidad de la República podemos encontrar al menos una disposición que incide directamente en el ejercicio de la $\mathrm{AV}$ en cuanto a las relaciones familiares.

El Código Civil de esta entidad, en su artículo 4.112, establece que «[1]a reproducción asistida a través de métodos de inseminación artificial solo podrá efectuarse con el consentimiento de la mujer a quien haya de practicarse dicho procedimiento», lo que en términos de $\mathrm{AV}$ nos parece correcto.

Sin embargo, en el segundo párrafo del mismo artículo se ordena que «[1]a mujer casada no podrá otorgar su consentimiento para ser inseminada, sin la conformidad de su cónyuge». Aquí encontramos una primera limitación a la AV de las mujeres, pero la historia no termina aquí, pues en el mismo párrafo, en su parte final, se establece que «[t]ampoco podrá dar en adopción al menor nacido, mediante este método de reproducción».

Así pues, si una mujer ha tenido hijos por medios naturales, sí podría dar en adopción a esos hijos, pero si el hijo se deriva del uso de un procedimiento de inseminación artificial, este hijo en particular no puede ser dado en adopción. Así pues, AV plena en términos de adopción cuando los hijos son producto del coito, pero AV restringida si el hijo es derivado de una inseminación artificial.

26 La ironía respecto de la expresión «personita» es nuestra. 


\section{CONCLUSIONES}

Como se adelantó, en México existen tantas legislaciones civiles como entidades de la República, lo que sin duda alguna está generando en nuestro país lo que podríamos denominar como «caos normativo», en temas tan trascendentes como la RHA esto por las implicaciones que tiene su utilización.

El Derecho de familia en México se encuentra en un proceso de transición muy complejo. México es un país que tiene muchas facetas. No hay un solo México, existen al menos treinta y dos, que es el número de entidades de la República que, por mandato constitucional, pueden legislar libremente en materia familiar.

Es por ello que, como investigadores jurídicos, hemos insistido que el tema de la RHA es uno que debe ser legislado desde una perspectiva federal o nacional. México necesita una legislación que armonice los diversos intereses que se ven involucrados en estos temas. El tener diversas legislaciones estatales solo fragmenta y provocan confusión e inseguridad jurídica para todas esas personas que, dado el avance de la ciencia, invariablemente desearían y tienen -sin duda alguna- el derecho de utilizar las diversas técnicas que ya existen y aquellas que seguirán surgiendo con el paso de los años.

La RHA es una realidad evidentemente mal entendida desde el Derecho mexicano. Esto es tan obvio que somos pocos los que nos hemos interesado en estos apasionantes temas, cuya trascendencia para el Derecho de familia es mucho más grande de lo que hasta hoy hemos podido apreciar.

La revolución biotecnológica es imparable, por lo que el jurista comprometido con el cambio social implicado por estos procedimientos debe preparase cada día más y mejor para, desde la trinchera del «Bioderecho», ofrecer respuestas a diversos fenómenos biojurídicos y biosociales que sin duda exigen una nueva visión normativa, una que obligadamente tiene un carácter multidisciplinar. El Derecho ya no puede mantenerse aislado de los avances biotecnológicos.

El abogado, el jurista y el legislador de esta época se ven obligado a interactuar con otras ciencias sociales. Derecho, trabajo social, sociología, filosofía, antropología e historia son, además de la biología y la genética, espectros del conocimiento que no pueden estar al margen de la discusión jurídica, de esa discusión que hoy, sin duda, merece el calificativo de «biojurídica» o de «Bioderecho».

\section{BIBLIOGRAFÍA}

ARANA DE LA FUENTE, I., «Concepto y función social del matrimonio. Los sistemas matrimoniales», en DIEZ PICAZO GIMÉNEZ, G. (coord.), Derecho de Familia, Pamplona (Thomson, Reuters-Civitas), 2012, pp. 165-270. 
BARBALUCCA, V. y GALLUCCI, P. L'autonomia negoziale dei coniugi nella crisi matrimoniale, Milán (Giuffrè) 2012.

BERNAL-FANDIÑO, M., «El principio de solidaridad como límite a la autonomía privada». Revista Jurídicas, 13 (2), julio-diciembre 2016, pp. 60-70. Disponible en $<$ http://vip.ucaldas.edu.co/juridicas/downloads/Juridicas13(2)_5.pdf $>$. [Consultado el 09/01/2019].

DE AMUNÁSTEGUI RODRÍGUEZ, C., «Libertad de pacto en el régimen de separación de bienes», en RAMS ALBESA, J. y otros (coords.), Autonomía de la voluntad y negocios jurídicos de familia, Madrid (Dykinson), 2009, pp. 117-272.

DOMINGUEZ HIDALGO, C., «Los principios que informan el derecho de familia chileno: su formulación clásica y su revisión moderna». Revista Chilena de Derecho, vol. 32, núm. 2, mayo-agosto, 2005, pp. 205-218. Disponible en $<$ https://papers. ssrn.com/sol3/papers.cfm?abstract_id=2640200>. [Consultado el 08/01/2019].

FENOUILLET, D. y VAREILLES-SOMMIÉRES, P. (dirs.), La contractualisation de la famille, París (Ed. Economica), 2001.

KEMELMAJER DE CARLUCCI, A., «La autonomía de la voluntad en el derecho de familia argentino», en GRAHAM, M. y HERRERA M. (dirs.), Derecho de las Familias, Infancia y Adolescencia. Una mirada crítica y contemporánea 1. a ed., Buenos Aires (Infojus), 2014, pp. 3-43. Disponible en < http://www.saij.gob.ar/ docs-f/ediciones/libros/DERECHO\%20DE\%20LAS\%20FLIAS\%20compl\%20 digital\%20(3).pdf >. [Consultado el 20/01/2019].

LAMM, E., Gestación por sustitución: ni maternidad subrogada ni alquiler de vientres, Barcelona (Universidad de Barcelona), 2013.

LÓPEZ AGUILAR, J. F., Derechos fundamentales y libertad negocial: sobre el espacio constitucional para la autonomía de la voluntad entre particulares, Madrid (Ministerio de Justicia), 1990.

MENDOZA CÁRDENAS, H.A., La Reproducción Humana Asistida desde una perspectiva Biojurídica, México (Fontamara), 2011.

ROMO MORALES, G., «La familia como institución y universal. Análisis de los cambios modernos», en ROMO MORALES, G. (coord.), La familia como institución. Cambios y permanencias, México (Ed. Universidad de Guadalajara), 2016, pp. 103-133.

SALINAS QUIJADA, F., «La autonomía de la voluntad en el artículo 90 del código civil en el derecho civil de Navara: sus concordancias y diferencias», Revista Ius Canonicum, 1982, Vol. XXII (N44), pp. 797-818 Disponible en $<\mathrm{https} / / /$ 
www.unav.edu/publicaciones/revistas/index.php/ius-canonicum/article/download/19206/15775>. [Consultado el 10/01/2019].

TOMMASINI, R, Autonomia privata e rimedi in trasformazione, Turín (Giappiche1li), 2013.

UNGARI, P., Bioética, nuevos derechos y autonomía de la voluntad, Buenos Aires (La Rocca), 2000.

VILLELA CORTÉZ F. y LINARES SALGADO J., «Diagnóstico genético prenatal y aborto. Dos cuestiones de eugenesia y discriminación», Revista de Bioética y Derecho, núm. 24, 2012, pp. 31 43. Disponible en <https://www.redalyc.org/ articulo.oa?id=78339726004>. [Consultado el 21/01/2019]. 